\title{
Blood contamination effect on shear bond strength of an orthodontic hydrophilic resin
}

Taís de Morais Alves da CUNHA ${ }^{1}$, Bruna Ariela BEHRENS², Denise NASCIMENTO², Luciana Borges RETAMOSO³ Luís Filipe Siu LON ${ }^{1}$, Orlando TANAKA ${ }^{4}$, Odilon GUARIZA FILHO ${ }^{5}$

\author{
1- DDS, MSc, Dental School, Pontifical Catholic University of Paraná, Curitiba, PR, Brazil. \\ 2- Undergraduate student, Dental School, Pontifical Catholic University of Paraná, Curitiba, PR, Brazil. \\ 3- DDS, MSc, Postgraduate student, Department of Restorative Dentistry, Dental School, Pontifical Catholic University of Rio Grande do Sul, Porto Alegre, \\ RS, Brazil. \\ 4- DDS, MSc, PhD, Full Professor, Department of Orthodontics, Dental School, Pontifical Catholic University of Paraná, Curitiba, PR, Brazil. \\ 5- DDS, MSc, PhD, Adjunct Professor, Department of Orthodontics, Dental School, Pontifical Catholic University of Paraná, Curitiba, PR, Brazil.
}

Corresponding address: Dr. Orlando Tanaka - R. Imaculada Conceição, 1155 - Phone: (41) 32711637 - Fax: (41) 32711405 - $80215-901$ - Curitiba - Paraná - Brazil - e-mail: tanakaom@gmail.com

Received: November 25, 2009 - Modification: May 13, 2010 - Accepted: May 30, 2010

\section{ABSTRACT}

\begin{abstract}
$\mathrm{O}$ bjective: The aim of this study was to assess the impact of blood contamination on shear bond strength (SBS) and bond failure pattern of metallic brackets bonded using a new hydrophilic resin. Material and Methods: Eighty human premolars were randomly allocated into 4 groups $(n=20)$ according to the bonding material and contamination pattern. GI: brackets bonded with the Transbond XT conventional system without contamination; GII: brackets bonded with the Transbond XT conventional system with blood contamination; GIII: brackets bonded with the Transbond Self Etching Primer and Transbond Plus Color without contamination; GIV: brackets bonded with the Transbond Self Etching Primer and Transbond Plus Color with blood contamination. The specimens were stored in distilled water at $37^{\circ} \mathrm{C}$ for $24 \mathrm{~h}$ and then submitted to SBS test at a crosshead speed of $0.5 \mathrm{~mm} /$ min. After bond failure, the enamel surfaces were observed under an optical microscope at 40x magnification. Results: Blood contamination decreased $(P<0.05)$ shear bond strength when both the hydrophobic (GII) and the hydrophilic resin (GIV) were used. However, the bond strength of Transbond Color Change group was significantly higher $(P<0.05)$ than that of the Transbond XT conventional system group under blood contamination condition. Under dry conditions no difference was observed between the hydrophobic and hydrophilic resin groups. Regarding the bond failure pattern, when blood contaminated the enamel, the adhesive remnant index (ARI) showed predominance of scores 0 and 1 , which indicates low adhesion to enamel. Conclusions: Although there was a significant decrease in the shear bond strength for both adhesive systems under blood contamination, the hydrophilic system showed significantly higher bond strength than the hydrophobic resin adhesive. Therefore, it is advisable to use the hydrophilic resin under risk of blood contamination.
\end{abstract}

Key words: Orthodontic brackets. Shear strength. Dental bonding.

\section{INTRODUCTION}

The appearance of orthodontic fixed appliances has been revolutionized since Newman ${ }^{18}$ (1965) suggested an orthodontic use for the enamel direct bonding technique. Over the years a great deal of attention has been paid to improve the acid-etching technique, primers and adhesives. Traditional composite resin bonding materials present hydrophobic properties and require dry surfaces to obtain clinically acceptable bond strength ${ }^{13}$. Thus, contamination during orthodontic bonding process is undesirable because it interferes on the adhesive and resin properties and causes failure on the adhesive interface.

A variety of clinical conditions forbid ideal isolation of the bonding site ${ }^{9,12}$, especially around second molars or partially erupted and impacted teeth submitted to surgical exposure ${ }^{6}$. Saliva or blood contamination are considered the most 
common reason for bond failure ${ }^{8,21,22}$ because when etched enamel becomes wet, most of the pores become plugged, and resin penetration is impaired, resulting in insufficient resin tags ${ }^{21}$. Thus, it would be advantageous the ability of bonding to enamel in a wet environment. For this reason, manufacturers introduced hydrophilic primers that promised successful bonding to a contaminated enamel surface. More recently, hydrophilic self-etching primers were developed to combine conditioning and priming agents into a single acidic primer, eliminating phases in the process ${ }^{17}$. These products have the advantage of a faster and simplified technique.

However, composite resins maintained hydrophobic characteristics. Currently, in an attempt to solve contaminating problems, manufacturers introduced Transbond Plus Color Change ( $3 \mathrm{M}$ Unitek, St. Paul, MN, USA), a hydrophilic composite resin.

Some researches $7,10,12$ have reported a decline in bracket bond strength as a result of blood exposure during bond. However, these studies used hydrophilic primer with hydrophobic adhesive resin and none have investigated whether there was any difference in bond strength values when hydrophilic adhesive resin is associated with hydrophilic primer.

The purpose of this study was to evaluate the efficacy of the Transbond Plus Color Change associated with Transbond Self Etching Primer used to bond metallic brackets under blood contamination condition.

\section{MATERIAL AND METHODS}

A total of 80 human extracted premolars from the teeth bank of Pontifical Catholic University of Paraná (PUCPR), Brazil, were used for this investigation. The roots were removed and the crowns were embedded in autopolymerized acrylic resin so that the buccal surface of each tooth was parallel to the base of the polymer.

Before bracket bonding, the buccal surface of each premolar was cleaned with slurry of water and pumice (Quimidrol Ltda., Joinville, SC, Brazil) for 10 $s$ with a rubber cup on a low-speed handpiece. The enamel surface was rinsed with water to remove pumice and debris and dried with an oil-free air stream for $10 \mathrm{~s}$. Eighty specimens were randomly allocated to 4 different groups $(n=20)$, according to Figure 1.

Orthodontic stainless-steel standard premolar brackets with a 0.022 -inch slot and $14.28 \mathrm{~mm}^{2}$ of bonding area (3M Unitek, St. Paul, MN, USA) were bonded to the dental enamel on the $\mathrm{G} 1$ and $\mathrm{G} 2$ using the Transbond $\mathrm{XT}^{\circledR}$ system (3M Unitek). The enamel surface was etched with $37 \%$ phosphoric acid for $15 \mathrm{~s}$, rinsed with distilled water for $10 \mathrm{~s}$, air-dried for $10 \mathrm{~s}$ and conventional primer Transbond XT was applied. Then, the bracket with adhesive resin Transbond XT was positioned on the enamel surface and pressed with $400 \mathrm{kgf}$, using a dynamometer (ETM). Excess of adhesive was removed around the bracket base and the adhesive was light cured by an Ortholux XT lamp (3M Unitek, St. Paul, MN, USA) on each interproximal side for $10 \mathrm{~s}$.

The brackets on G3 and G4 were bonded with Transbond Self Etching Primer (SEP, 3M Unitek) associated with the composite resin Transbond Plus Color Change Adhesive (3M Unitek), which presents hydrophilic characteristic. Self-etching primer was pressed in contact to the enamel surface for $10 \mathrm{~s}$. The adhesive resin Transbond Plus Color Change was inserted to the bracket base, the bracket was positioned on the enamel and pressed with $400 \mathrm{Kgf}$, using a dynamometer. The excess adhesive was removed around the bracket and the adhesive was light-cured with an Ortholux XT lamp (3M Unitek) on each interproximal side for $10 \mathrm{~s}$.

The specimens of $\mathrm{G} 1$ and $\mathrm{G} 3$ were bonded without contamination and of G2 and G4 under blood contamination. The contamination was performed immediately before Transbond XT paste and Transbond Plus Color Change application. To achieve reproducible conditions, the teeth in the blood-contaminated groups were treated with fresh human blood from one female donor and blood was applied with a brush into the buccal surfaces for 10 $s$ to permit full hydration of the surface.

\section{Shear bond strength test}

After bonding, all samples were stored in distilled water at $37^{\circ} \mathrm{C}$ for $24 \mathrm{~h}$ and then tested in a shear mode on a universal testing machine (EMIC DL 500, EMIC, São José dos Pinhais, PR, Brazil). Specimens were secured in the lower jaw of the machine so that the bonded bracket base was percentile to the shear force direction. Specimens were stressed in an occlusogingival direction at a crosshead speed of $0.5 \mathrm{~mm}$ per minute. The maximum load necessary to debond or initiate bracket fracture was recorded

\begin{tabular}{|c|c|c|}
\hline Group & Contamination & Adhesive System \\
\hline G1 & None & $\begin{array}{c}\text { Transbond XT primer and } \\
\text { Transbond XT }\end{array}$ \\
\hline G2 & Blood & $\begin{array}{c}\text { Transbond XT primer and } \\
\text { Transbond XT }\end{array}$ \\
\hline G3 & None & $\begin{array}{c}\text { Transbond Self Etching } \\
\text { primer and Transbond Plus } \\
\text { Color }\end{array}$ \\
\hline G4 & Blood & $\begin{array}{c}\text { Transbond Self Etching } \\
\text { primer and Transbond Plus } \\
\text { Color }\end{array}$ \\
\hline
\end{tabular}

Figure 1- Experimental groups 
Table 1- Descriptive statistic for shear bond strength

\begin{tabular}{ccccc}
\hline Groups & Contamination & Composite Resin & Mean (MPa) & SD \\
\hline G1 & None & Transbond XT & 8.94 & $\pm 3.97^{\mathrm{A}}$ \\
G2 & Blood & Transbond XT & 2.15 & $\pm 1.22^{\mathrm{B}}$ \\
G3 & None & Transbond Plus & 9.91 & $\pm 2.23^{\mathrm{A}}$ \\
G4 & Blood & Transbond Plus & 5.24 & $\pm 2.45^{\mathrm{C}}$ \\
\hline
\end{tabular}

Different letters indicates statistical difference for Games Howell test $p<0.05 . S D=$ standard deviation

Table 2- Descriptive statistics for Adhesive Reminiscent Index (ARI)

\begin{tabular}{cccccccc}
\hline Groups & $\mathbf{n}$ & Contamination & Resin & \multicolumn{3}{c}{ Scores ARI (\%) } \\
& & & & 0 & 1 & 2 & 3 \\
\hline G1 & 20 & None & Transbond XT & 40 & 30 & 10 & 20 \\
G2 & 20 & Blood & Transbond XT & 90 & 10 & 0 & 0 \\
G3 & 20 & None & Transbond Plus & 25 & 30 & 25 & 20 \\
G4 & 20 & Blood & Transbond Plus & 55 & 25 & 15 & 5 \\
\hline
\end{tabular}

in Newtons and then converted into MPa.

After bond failure, bracket bases and the enamel surfaces were examined under a stereomicroscope (Olympus Optical Co., Shinjuku, Tokyo, Japan) at 10x magnification. The adhesive reminiscent index (ARI) was used to assess the amount of adhesive left on the enamel surface ${ }^{1}$.

\section{Statistical analysis}

Statistical calculations were performed by the Statistical Package for the Social Sciences Version 15.0 software (SPSS 15.0, SPSS Inc., Chicago, IL, USA) for Windows. In addition to standard descriptive statistical calculations (mean and standard deviation), Kolmogorov-Smirnov and Levene test were performed.

The one-way ANOVA was carried out for the comparison of groups. In the evaluation of subgroups, a Games-Howell multiple comparison test was performed. The statistical significance level was established at $\mathrm{P}<0.05$.

\section{RESULTS}

\section{Shear bond strength}

ANOVA demonstrated that material and contamination altered shear bond strength. The hydrophobic conventional Transbond XT system revealed a significant $(P<0.05)$ decrease in SBS after blood contamination. A significant $(P<0.05)$ decrease in SBS could also be detected after blood contamination using Transbond Plus Color Change (Table 1).

The bond strength of Transbond Plus Color Change group was significantly higher than for Transbond $\mathrm{XT}$ group under blood contamination condition $(P<0.05)$. Under dry conditions no difference was observed between the hydrophobic and hydrophilic adhesive resin groups (Table 1 ).

\section{Adhesive reminiscent index (ARI)}

Groups without contaminants demonstrated balanced distribution of ARI scores. When blood contaminated the enamel, there was a predominance of ARI scores 0 and 1 , indicating low adhesion to enamel. The frequency of ARI scores is presented in Table 2.

\section{DISCUSSION}

The difficulty of orthodontic bracket bonding is its semi-permanent nature. The bond strength should be sufficiently high to resist accidental debonding during treatment, but low enough to remove the bracket from the tooth without generating excessive force which might damage the periodontal tissue or the enamel surface ${ }^{19}$. Bracket undesirable debonding often results from failure in the bonding technique, low retentiveness of bracket bases and masticatory forces ${ }^{15}$. It might delay treatment finishing and increase the costs of fixed orthodontic appliances ${ }^{20}$. In an attempt to minimize these problems, the dental industry has been incessantly developed hydrophilic bonding materials capable to withstanding the Orthodontic and masticatory forces.

It is important to choose the appropriate material for bonding in orthodontics, regarding factors such as resistance, longevity and easy to remove without damaging the enamel surface. Those in vitro characteristics support the clinical practice through the shear bond strength and ARI scores $^{23}$. The correlation between in vitro and in vivo adhesive/resin interfaces and bond strength tests 
has been shown elsewhere ${ }^{25}$. It is a common belief that the clinically adequate SBS for a stainless steel bracket to enamel should be 6-8 $\mathrm{MPa}^{4,11,19}$.

Moisture contamination is still a problem during direct bonding of orthodontic brackets, especially while bonding posterior teeth as well as surgically exposed teeth, so the saliva and the blood are the principal contaminant agents in this process ${ }^{21}$.

Previous studies demonstrated decrease on bond strength when self etching primers were used under dry conditions $3,16,25,26$. In contrast, Webster, et al. ${ }^{24}$ (2001) concluded that uncontaminated enamel surfaces resulted in the highest bond strengths for hydrophilic and hydrophobic adhesives. In the present study, no significant difference between conventional Transbond XT system and SEP/ Transbond XT Color Change could be observed under dry conditions and both showed clinical satisfactory values of SBS.

The impact of blood contamination on bond strength has been tested before. The results of SBS tests indicate that human blood seems to be a great barrier for the adhesives to penetrate. This might be of concern when bonding orthodontic buttons or brackets during surgical exposure of impacted teeth. Often glass ionomer cements (GICs) are used for bonding brackets to the surface of unerupted teeth, because of their enhanced curing in a wet environment ${ }^{22}$. However, Reddy, et al. $^{22}$ (2003) found that the beneficial wetting phenomenon of GICs is not achieved after blood contamination during curing. They stated that, without contamination, composite resins have greater bond strength than resin-reinforced GICs. After blood contamination, both materials showed a significant decrease in bond strength ${ }^{22}$.

Previous studies have demonstrated a decrease in the bond strength due to blood contamination during the bracket bond process ${ }^{7,10,12}$. However these studies used the hydrophilic primer with a hydrophobic resin. In the present study a hydrophilic adhesive resin was tested associated to the self etching primer under blood contamination, it was possible to observe higher values than those observed when the hydrophobic resin was used.

In the present study, blood constituted a physical barrier preventing the mechanical retention of the adhesive to the etched tooth and the hydrophilic adhesive resin do not solve this problem. Thus, even with the application of a self-etching primer associated with a hydrophilic resin, the bond strength of bracket bonded under blood contamination is not capable to withstand clinical forces. Yet, the hydrophilic system showed significantly higher bond strength that the hydrophobic resin adhesive. Therefore, under a risk of blood contamination it is advisable to use the hydrophilic resin.

Relating to the bracket debonding, Bishara, et al. $^{2}$ (1999) stated that when the failure occurs at the enamel/adhesive interface there is an increased risk of enamel fracture. However, if the failure occurs in the interface adhesive/bracket, the enamel is often preserved $5,14,25$. When blood contaminated the enamel, ARI showed predominance of scores 0 and 1 , indicating low adhesion to enamel, thus the adhesives used in this investigation do not present risk to enamel integrity. Moreover, this result indicates a minimum amount of adhesive remaining on teeth, clinically, this would imply a minimal clean-up time after debonding and no risk to damage the dental enamel.

Under dry conditions hydrophobic primers and resins can be applied, but if contamination during bonding is expected, we recommend the use of a hydrophilic primer associated with a hydrophilic resin. However, blood contamination is a serious problem for bond strength, so this type of contamination must be avoided during brackets bonding process.

\section{CONCLUSIONS}

There was no significant difference in the bond strength of Transbond XT and Transbond Plus Color Change under dry conditions.

Transbond XT and the Transbond Plus Color Change showed clinically acceptable bond strength for brackets bonded to dental enamel under dry conditions.

Blood contamination decreased the shear bond strength of orthodontic brackets bonded with Transbond XT hydrophobic adhesive resin and with the hydrophilic adhesive resin Transbond Plus Color Change.

Under blood contamination, the hydrophilic resin Transbond Plus Color Change associated to the Self Etching Primer led to significantly higher bond strength than the conventional Transbond XT system.

\section{REFERENCES}

1- Artun J, Bergland S. Clinical trials with crystal growth conditioning as an alternative to acid-etch enamel pretreatment. Am J Orthod. 1984;85(4):333-40.

2- Bishara SE, Gordan VV, VonWald L, Jakobsen JR. Shear bond strength of composite, glass ionomer, and acid primer adhesive systems. Am J Orthod Dentofacial Orthop. 1999;115(1):24-8. 3- Bishara SE, VonWald L, Laffoon JF, Warren JJ. Effect of a selfetch primer/adhesive on the shear bond strength of orthodontic brackets. Am J Orthod Dentofacial Orthop. 2001;119(6):621-4. 4- Bourke BM, Rock WP. Factors affecting the shear bond strength of orthodontic brackets to porcelain. Br J Orthod. 1999;26(4):28590.

5- Brown CR, Way DC. Enamel loss during orthodontic bonding and subsequent loss during removal of filled and unfilled adhesives. Am J Orthod. 1978;74(6):663-71. 
6- Cacciafesta V, Sfondrini MF, De Angelis M, Scribante A, Klersy C. Effect of water and saliva contamination on shear bond strength of brackets bonded with conventional, hydrophilic, and self-etching primers. Am J Orthod Dentofacial Orthop. 2003;123(6):633-40. 7- Cacciafesta V, Sfondrini MF, Scribante A, De Angelis M, Klersy C. Effects of blood contamination on the shear bond strengths of conventional and hydrophilic primers. Am J Orthod Dentofacial Orthop. 2004;126(2):207-12.

8- Campoy MD, Vicente A, Bravo LA. Effect of saliva contamination on the shear bond strength of orthodontic brackets bonded with a self-etching primer. Angle Orthod. 2005;75(5):865-9.

9- Dorminey JC, Dunn WJ, Taloumis LJ. Shear bond strength of orthodontic brackets bonded with a modified 1-step etchantand-primer technique. Am J Orthod Dentofacial Orthop. 2003;124(4):410-3.

10- Faltermeier A, Behr M, Rosentritt M, Reicheneder C, Müssig D. An in vitro comparative assessment of different enamel contaminants during bracket bonding. Eur J Orthod. 2007;29(6):559-63.

11- Gillis I, Redlich M. The effect of different porcelain conditioning techniques on shear bond strength of stainless steel brackets. Am J Orthod Dentofacial Orthop. 1998;114(4):387-92.

12- Hobson RS, Ledvinka J, Meechan JG. The effect of moisture and blood contamination on bond strength of a new orthodontic bonding material. Am J Orthod Dentofacial Orthop. 2001;120(1):54-7.

13- Hormati AA, Fuller JL, Denehy GE. Effects of contamination and mechanical disturbance on the quality of acid-etched enamel. J Am Dent Assoc. 1980;100(1):34-8.

14- Joseph VP, Rossouw PE. The shear bond strengths of stainless steel orthodontic brackets bonded to teeth with orthodontic composite resin and various fissure sealants. Am J Orthod Dentofacial Orthop. 1990;98(1):66-71.

15- Katona TR, Long RW. Effect of loading mode on bond strength of orthodontic brackets bonded with 2 systems. Am J Orthod Dentofacial Orthop. 2006;129(1):60-4.

16- Littlewood SJ, Mitchell L, Greenwood DC, Bubb NL, Wood DJ. Investigation of a hydrophilic primer for orthodontic bonding: an in vitro study. J Orthod. 2000;27(2):181-6.
17- Moura SK, Reis A, Pelizzaro A, Dal-Bianco K, Loguercio AD, Arana-Chavez VE, et al. Bond strength and morphology of enamel using self-etching adhesive systems with different acidities. J Appl Oral Sci. 2009;17(4):315-25

18- Newman GV. Epoxy adhesives for orthodontic attachments: progress report. Am J Orthod. 1965;51(12):901-12.

19- Özcan M, Vallittu PK, Peltomäki T, Huysmans MC, Kalk W. Bonding polycarbonate brackets to ceramic: effects of substrate treatment on bond strength. Am J Orthod Dentofacial Orthop. 2004;126(2):220-7.

20- Python MM, Oliveira MV, Ruellas ACO, Bolognese AM, Romano $\mathrm{FL}$. Shear bond strength of orthodontic brackets to enamel under different surface treatment conditions. J Appl Oral Sci. 2007;15(2):127-30.

21-Rajagopal R, Padmanabhan S, Gnanamani J. A comparison of shear bond strength and debonding characteristics of conventional, moisture-insensitive, and self-etching primers in vitro. Angle Orthod. $2004 ; 74(2): 264-8$.

22- Reddy L, Marker VA, Ellis E $3^{\text {rd }}$. Bond strength for orthodontic brackets contaminated by blood: composite versus resin-modified glass ionomer cements. J Oral Maxillofac Surg. 2003;61(2):20613.

23- Retamoso LB, Collares FM, Ferreira ES, Samuel SMW. Shear bond strength of metallic brackets: influence of saliva contamination. J Appl Oral Sci. 2009;17(3):190-4.

24- Webster MJ, Nanda RS, Duncanson MG Jr, Khajotia SS, Sinha PK. The effect of saliva on shear bond strengths of hydrophilic bonding systems. Am J Orthod Dentofacial Orthop. 2001;119(1):54-8.

25- Yamada R, Hayakawa T, Kasai K. Effect of using selfetching primer for bonding orthodontic brackets. Angle Orthod. 2002;72(6):558-64.

26- Zeppieri IL, Chung CH, Mante FK. Effect of saliva on shear bond strength of an orthodontic adhesive used with moistureinsensitive and self-etching primers. Am J Orthod Dentofacial Orthop. 2003;124(4):414-9. 